\title{
Effects of a Nanoceria Fuel Additive on Physicochemical Properties of Diesel Exhaust Particles
}

Junfeng (Jim) Zhang ${ }^{\mathrm{a}, *}$, Ki-Bum Lee $^{\mathrm{b}}$, Linchen $\mathrm{He}^{\mathrm{a}}$, Joanna Seiffert ${ }^{\mathrm{c}}$, Prasad Subramaniam ${ }^{\mathrm{b}}$, Letao Yang $^{\mathrm{b}}$, Shu Chen $^{\mathrm{c}}$, Pierce Maguire ${ }^{\mathrm{c}}$, Gediminas Mainelis ${ }^{\mathrm{d}}$, Stephan Schwander ${ }^{\mathrm{e}}$, Teresa Tetley ${ }^{\mathrm{c}}$, Alexandra Porter ${ }^{\mathrm{c}}$, Mary $^{-}$ Ryan $^{\mathrm{f}}$, Milo Shaffer ${ }^{\mathrm{f}}$, Sheng Hu${ }^{\mathrm{f}}$, Jicheng Gong ${ }^{\mathrm{a}}$ and Kian Fan Chung ${ }^{\mathrm{c}}$

${ }^{a}$ Nicholas School of the Environment, and Duke Global Health Institute, Duke University, Durham, NC

${ }^{\mathrm{b}}$ Department of Chemistry and Chemical Biology, Rutgers University, Piscataway, NJ

${ }^{\mathrm{c}}$ National Heart and Lung Institute, Imperial College London, London, UK

${ }^{\mathrm{d}}$ Department of Environmental Sciences, Rutgers University, Piscataway, NJ

${ }^{\mathrm{e}}$ School of Public Health, Rutgers University, Piscataway, NJ

${ }^{\mathrm{f}}$ Department of Materials and London Centre for Nanotechnology, Imperial College London, London, UK

* Address all correspondence to Prof. J. Zhang, 919-681-7782, email: junfeng.zhang@duke.edu 


\section{ABSTRACT:}

Nanoceria (i.e., $\mathrm{CeO}_{2}$ nanoparticles) fuel additives have been used in Europe and elsewhere to improve fuel efficiency. Previously we have shown that the use of a commercial fuel additive Envirox ${ }^{\text {TM }}$ in a diesel-powered electricity generator reduced emissions of diesel exhaust particle (DEP) mass and other pollutants. However, such additives are currently not permitted for use in on-road vehicles in North America, largely due to limited data on the potential health impact. In this study, we characterized a variety of physicochemical properties of DEPs emitted from the same engine. Our methods include novel techniques such as Raman spectrometry for analyzing particle surface structure and an assay for DEP oxidative potential. Results show that with increasing Envirox $^{\mathrm{TM}}$ concentrations in the fuel $\left(0 \mathrm{x}, 0.1 \mathrm{x}, 1 \mathrm{x}\right.$, and 10x of manufacturer recommended 0.5 ml Envirox $^{\mathrm{TM}}$ per $^{-1}$ liter fuel), DEP sizes decreased from $194.6 \pm 20.1$ to $116.3 \pm 14.8 \mathrm{~nm}$; zeta potential changed from $-28.4 \mathrm{mV}$ to $22.65 \mathrm{mV}$; DEP carbon content decreased from $91.8 \%$ to $79.4 \%$; cerium and nitrogen contents increased from $0.3 \%$ to $6.5 \%$ and $0.2 \%$ to $0.6 \%$, respectively; the ratio of organic carbon (OC) to elemental carbon (EC) increased from $22.9 \%$ to $38.7 \%$; and the ratio of disordered carbon structure to ordered carbon structure (graphitized carbon) in DEP decreased. Compared to DEPs emitted from 0x, 0.1x, and 1x fuels, DEPs from the 10x fuel had a lower oxidative potential likely due to increased ceria content because pure ceria nanoparticles exhibited the lowest oxidative potential compared to all the DEPs. Since the physicochemical parameters tested here are among the determinants of particle toxicity, our findings imply that adding ceria nanoparticles into diesel may alter the toxicity of DEPs. The findings from the present study, hence, can help future studies that will examine the impact of nanoceria additives on DEP toxicities. 


\section{Introduction}

Diesel exhaust particles (DEPs) have been used in numerous toxicological studies to understand the health effects of particulate air pollution and underlying biological mechanisms of those effects. ${ }^{1,2}$ A major reason for using DEPs as a model pollutant is their unique physicochemical properties: carbonaceous core and highly adsorptive surfaces. It is also well recognized, however, that not all DEPs have the same physicochemical properties due to difference in combustion conditions and other factors affecting the formation and emission of DEPs. ${ }^{3,4}$ Fuel catalyst additives may be a modifying factor of DEP toxicity.

Fuel additives formulated with ceria $\left(\mathrm{CeO}_{2}\right)$ nanoparticles have been used in Europe, Asia Pacific, North America (limited to off-road engines), and South America, as these additives serve as a combustion catalyst leading to improved fuel efficiency. ${ }^{5}$ Several previous studies found that nano ceria as a fuel additive is able to shift DEP size distributions toward smaller particle sizes ${ }^{6,7}$ increase their oxidation rate, ${ }^{6}$ and alter their chemical composition. ${ }^{7,8}$ In an earlier paper, in addition to these findings, we reported that using a commercial fuel additive containing $\mathrm{CeO}_{2}$ nanoparticles (Envirox ${ }^{\mathrm{TM}}$, Energenics Europe Ltd., U.K.) in a diesel power generator resulted in a reduction of fuel consumption per unit of electricity generated, accompanied with reduced emissions of DEP mass, carbon dioxide, carbon monoxide, formaldehyde, acetaldehyde, acrolein, and increased oxides of nitrogen $\left(\mathrm{NO}_{\mathrm{x}}\right) .^{9}$

These findings point to the potential benefits of using Envirox ${ }^{\mathrm{TM}}$ and other nanoceria-based diesel additives in reducing environmental and health impacts. For example, the reduction in the emission of DEP mass and other air pollutants such as aldehydes could reduce cardiorespiratory health risks associated with diesel exhaust exposure. ${ }^{10}$ However, this benefit may be reversed if DEPs released from nanoceria-treated fuels are more toxic than DEPs emitted from untreated fuels. An important question remains as to whether the use of Envirox ${ }^{\mathrm{TM}}$ would potentially change the toxicity of emitted DEPs emitted. In order to answer this question, the physicochemical properties of the DEPs, which are the key determinants of toxicity, needed to be assessed. However, previous studies have focused more on reaction mechanisms by which ceria nanoparticles affect the combustion process and pollutant emissions. ${ }^{6,12,13}$ Few studies have characterized physicochemical properties of DEPs. The present study aims to conduct a comprehensive analysis of DEP 
physiochemical properties including size, morphology, chemical composition, surface charge, crystalline structure, and oxidative potential of DEPs emitted from combusting diesel with varying concentrations of Envirox $^{\mathrm{TM}}$ in a diesel-powered electric generator. ${ }^{9}$ The findings are expected to help future studies that will examine the impact of nanoceria diesel additives on the toxicity of DEPs.

\section{Materials and methods}

The experimental setup is only briefly described below as it has been previously reported. ${ }^{9}$

2.1. Diesel engine, fuel additive, and fuels

The "base fuel" used in this study was No.2 ultra-low $(<15 \mathrm{ppm})$ sulfur diesel purchased at a fuel station in New Jersey in January 2013. The fuel additive, Envirox ${ }^{\mathrm{TM}}$, was purchased from Energenics Europe Ltd., U.K., in 2011, and the ceria inside was in the form of 5-10 $\mathrm{nm}$ spherical $\mathrm{CeO}_{2}$ particles. ${ }^{14}$ The manufacturer

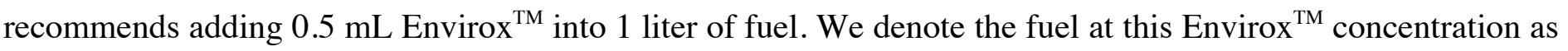
1x fuel. We also conducted experiments with the following Envirox ${ }^{\mathrm{TM}}$ concentrations in diesel: no Envirox ${ }^{\mathrm{TM}}$ added (0x), $0.05 \mathrm{~mL}$ Envirox ${ }^{\mathrm{TM}}$ per liter diesel $(0.1 \mathrm{x})$, and $5 \mathrm{~mL}$ Envirox ${ }^{\mathrm{TM}}$ per liter base fuel (10x). The theoretical concentrations of nanoceria in $0 \mathrm{x}, 0,1 \mathrm{x}, 1 \mathrm{x}$, and $10 \mathrm{x}$ fuels were $0,0.9,9$, and $90 \mu \mathrm{g} / \mathrm{mL}$, respectively. ${ }^{9}$ The diesel engine used in this study was a four-cycle, $406 \mathrm{cc}$ electric generator with one cylinder (Model YDG 5500EE, Yanmar Inc., Adairsville, GA), and it was operated under full load to provide $5.5 \mathrm{~kW}$ electricity.

\subsection{Collection and extraction of DEP}

A portion of the diesel exhaust exiting the exhaust pipe was directed into a mixing box $(50 \mathrm{~cm} \times 50 \mathrm{~cm} \times 60$ $\mathrm{cm}$ ), where it was mixed with purified air (i.e., ambient air that passed through an air purification system consisting of a fiberglass filter followed by a HEPA filter and then an activated carbon filter). The diluted diesel exhaust entered a $25 \mathrm{~m}^{3}$ stainless steel chamber through a stainless steel air diffuser. Relative humidity and temperature in the chamber were kept at $40-41 \%$ and $22-23{ }^{\circ} \mathrm{C}$, respectively. The dilution of the exhaust was controlled so as to result in an airborne particle concentration of $400 \pm 80 \mu \mathrm{g} / \mathrm{m}^{3}$, as measured by a calibrated SidePak photometer (AM510, TSI Inc., Shoreview, MN). This concentration was representative of a realistic ambient airborne diesel concentration. Particles were collected on $37 \mathrm{~mm}$ Teflon filters with a membrane ring 
(Pall Life Sciences, Ann Arbor, MI) from the center of the chamber using a pump operating at a flow rate of 10 L/min for 2.5-3 hours. DEPs were also collected on quartz fiber filters (Whatman QM-A 37 mm, part number 1851-037) for analysis of elemental carbon and organic carbon (see 2.5 below). Prior to use, the quartz filters were heat treated (at $500{ }^{\circ} \mathrm{C}$ for 2 hours) to remove organic impurities.

Particles collected on the Teflon filters were sonicated continuously for 2 hours at $25^{\circ} \mathrm{C}$ in $10 \mathrm{~mL}$ of highperformance liquid chromatography (HPLC)-grade water (Sigma Co., St. Louis, MO) in an ultrasonic machine (3510R-DTH, 100W, 42 KHZ, Branson Ultrasonics Co., Danbury, CT) at $100 \mathrm{~W}$ output to suspend the particles into the water. This sonication protocol was finally selected after we had performed a set of optimization experiments, as the selected protocol generated DEP sizes that were the closest to the sizes of airborne DEPs (see Supplemental Information). At the end of the sonication procedure, the filters were carefully removed and dried, and then weighed to obtain particle extraction efficiency (see Table $\mathbf{S 2}$ in Supplemental Information). DEP suspensions were distributed into different vessels and then stored in a refrigerator at $4^{\circ} \mathrm{C}$ before their further use. Immediately before each use, the DEP suspensions were further sonicated for 5 minutes to ensure uniform particle dispersion. To avoid potential microbiological contamination, all glassware was heat treated at $120^{\circ} \mathrm{C}$ in an oven overnight before use.

\subsection{DEP sizes and zeta potential}

Hydrodynamic size and zeta potential of the DEP samples were measured using a Zetasizer dynamic light scattering instrument (ZS Nano, Malvern Instruments, Malvern, UK) at a fixed temperature of $25^{\circ} \mathrm{C}$ and with a detection angle of 90 degrees. Before measurement, DEP water suspensions were diluted to $50 \mu \mathrm{g} / \mathrm{ml} \mathrm{using}$ phosphate-buffered saline buffer (PBS, $\mathrm{pH}=7.4)$ and were sonicated for 5 minutes in a bath sonicator (Branson 5510, Branson Electronics, Danbury, CT). This dilution and sonication procedure was appropriate for making DEP suspension solutions for toxicological testing. ${ }^{15}$ The samples were placed in the center of the sonicator to get maximal sonication power. For each batch of the DEP $(0 x, 0.1 x, 1 x$, and $10 x)$, particles in 3 sets of the suspensions were measured in parallel to obtain averages and standard deviations. For each sample, the size and zeta potential values were averaged over 11 repeated analysis runs. 


\subsection{DEP morphology}

An aliquot of DEP suspensions was dispersed in ethanol by sonication for $1 \mathrm{~min}$. A single drop of the suspension was then drop casted onto 300-mesh holey carbon film transmission electron microscope (TEM) grids (TAAB) and dried under vacuum. High resolution transmission electron microscopy (HRTEM) and high angle annular dark field scanning transmission electron microscopy (HAADF-STEM), combined with energydispersive X-ray spectroscopy (EDX) analysis, were carried out using an FEI Titan 80/300 fitted with a Cs (image) corrector, monochromator, and EDX detector (EDAX, Leicester, UK) operated at an accelerating voltage of $300 \mathrm{kV}$. For STEM experiments, a convergence semi-angle of 14 mrad was used, with an inner and outer HAADF collection angle of 49 and $239 \mathrm{mrad}$, respectively.

\subsection{DEP chemical composition}

In parallel to the DEP collection on Teflon filters as described above, diluted DEPs in the test chamber were collected onto quartz fiber filters (Pallflex, Port Washington, NY) at a flow rate of $1 \mathrm{~L} / \mathrm{min}$. Prior to use, the quartz fiber filters were heat-treated at $700{ }^{\circ} \mathrm{C}$ for one hour to remove any organic impurities. The DEPs collected on these filters were analyzed for elemental carbon (EC) and organic carbon (OC) at a commercial laboratory (Sunset Laboratory Inc., Tigard, OR) using a thermal-optical method. ${ }^{16}$ The precision of the method, measured as a relative standard deviation, was $4-6 \%$. The detection limit of this method was in the order of 0.2 $\mu \mathrm{g} / \mathrm{cm}^{2}$ filter for both OC and EC. All the DEP samples had EC and OC concentrations at least one order of magnitude higher than the detection limit.

DEPs collected on the Teflon filters were analyzed for carbon, hydrogen, and nitrogen content using an elemental analysis technique at a commercial laboratory (Robertson-Microlit Laboratories, Ledgewood, NJ). The method involved microchemical combustion of $1.0 \mathrm{mg}$ of DEPs using a Perkin Elmer 2400 CHN Analyzer (Waltham, MA). High purity helium gas was used as the carrier and oxygen gas (99.9\%) was used for the combustion. The operating temperature was $950^{\circ} \mathrm{C}$. Acetanilide (NIST SRM 141d) was used as the calibrating standard. Standard results were within $\pm 0.3 \%$ of theoretical values. Combustion was performed in tin capsules (6 by $4 \mathrm{~mm}$, Elemental Microanalysis D1006 or equivalent). 
Cerium content of the DEP samples was analyzed using an inductively coupled plasma mass spectrometry (ICP-MS) method. In this method, an aliquot of each test DEP suspension was digested in a concentrated ultrapure nitric acid in a high-power microwave oven. After dilution with HPLC-grade water, the extract was analyzed on an ICP-MS system (Thermo Elemental Plasma Quad3, Thermo Scientific, Waltham, MA). NIST standards (NIST SRM3110 and NIST SM1811-002) were used for calibration. The detailed ICP-MS operating and quality control protocols can be found in a previous publication. ${ }^{17}$

\subsection{Raman spectroscopy}

Raman-mapping spectroscopic characterization was carried out on a Renishaw inVia Confocal Raman microscope (Renishaw plc, Wotton-under-Edge, UK). The system calibration was performed using an integrated silicon wafer prior to measurement. Raman maps were obtained using a red excitation laser (wavelength $633 \mathrm{~nm}$, intensity 100\%, scan time 30 seconds) under StreamlineTM mode (1800 lines/mm diffraction grating). No obvious damage to the carbon walls was observed after Raman analysis. Baseline correction, peak fitting, and peak integration were analyzed using WiRE4.1 software. ${ }^{18}$

\subsection{Ascorbate depletion assay of oxidative potential}

DEP oxidative potential was assessed using an assay in which DEP suspensions were added to an ascorbic acid (an antioxidant) solution. The oxidative potential of DEPs was measured as the depletion rate of ascorbic acid. In addition to the four DEPs (from 0x, 0.1x, 1x, and 10x Envirox $\left.{ }^{\mathrm{TM}}\right), \mathrm{CeO}_{2}$ particles $(<50 \mathrm{~nm}$ in diameter) and a DEP purchased commercially (NIST 2975) were included in this set of test for comparison. Each of these particle samples was incubated with a mixture of ascorbic acid and sodium ascorbate (total ascorbate concentration of $200 \mu \mathrm{mol} / \mathrm{L}, \mathrm{pH} \mathrm{7,2}$ hours, $37^{\circ} \mathrm{C}$ ) in 96-well plates (Greiner Bio-one Ltd., UK). Ascorbate depletion rate $(\mu \mathrm{M} /$ minute) was determined by measuring ascorbate ion concentrations on UV spectrometry at 265 nm (Spectramax 384, Molecular Devices Ltd., USA) every two minutes over a 2-hour period.

\section{Results and Discussion}

\subsection{Effects of Envirox ${ }^{\mathrm{TM}}$ on DEP size and surface electrical charge}

The results on number-weighted particle size and zeta potential values are shown in Table 1. For the size, the two replicate samples were in excellent agreement for $0.1 \mathrm{x}, 1 \mathrm{x}$, and $10 \mathrm{x}$ fuels, where the differences in mean 
sizes between the two replicates ranged from 0.9 to $9.5 \%$ : a larger difference (45\%) between the two replicates was observed for the $0 \mathrm{x}$ fuel. We were not able to ascertain a reason for the differing levels of reproducibility. Nonetheless, based on the average values from the two replicate samples, there is a clear trend that as nanoceria concentration in the diesel fuel increased, the size of DEPs decreased. From 0x to 10x, DEP sizes decreased by $40 \%$ from $194.6 \mathrm{~nm}$ to $116.3 \mathrm{~nm}$. This trend was in agreement with previous findings with airborne DEPs (i.e., DEPs in the air of the test chamber before undergoing filter collection and subsequent extraction) by our group ${ }^{9}$ and others ${ }^{6}$. This trend was mainly due to the fact that adding ceria nanoparticles increasing the soot oxidative process, which led to a reduction in the size of agglomerated particles by breaking them down into smaller particles..$^{9,19-21}$ This mechanism also implies that increasing nanoceria in the diesel resulted in increased particle number concentrations and increased particle surface area per unit mass of DEP emitted. ${ }^{9}$ In agreement with our previous study, adding Envirox ${ }^{\mathrm{TM}}$ resulted in a reduction in DEP mass emissions and a net increase in ultrafine particle number emissions per unit electricity generated. ${ }^{9}$

Table 1. Particle size and zeta potential values for DEPs emitted from the four diesel fuels with varying Envirox $^{\mathrm{TM}}$ concentration.

\begin{tabular}{|c|c|c|c|c|c|}
\hline & Sample \# & $0 \times$ & $0.1 \times$ & $1 \times$ & $10 \times$ \\
\hline \multirow{3}{*}{ Size $(\mathrm{nm})$} & 1 & $230.3( \pm 25.9)$ & $143.3( \pm 12.0)$ & $134.4( \pm 19.0)$ & $115.8( \pm 14.4)$ \\
\cline { 2 - 6 } & 2 & $158.8( \pm 11.9)$ & $147.4( \pm 16.6)$ & $147.2( \pm 11.4)$ & $116.8( \pm 15.1)$ \\
\cline { 2 - 6 } & Average & $194.6( \pm 20.1)$ & $145.4( \pm 14.5)$ & $140.8( \pm 15.7)$ & $116.3( \pm 14.8)$ \\
\hline \multirow{2}{*}{ Zeta Potential } & 1 & $-26.2( \pm 2.5)$ & $-28.4( \pm 2.7)$ & $-32.2( \pm 2.2)$ & $-24.6( \pm 1.8)$ \\
\cline { 2 - 6 }$(\mathrm{mV})$ & 2 & $-30.6( \pm 2.0)$ & $-28.4( \pm 2.6)$ & $-28.1( \pm 1.8)$ & $-20.7( \pm 2.3)$ \\
\cline { 2 - 6 } & Average & $-28.4( \pm 2.3)$ & $-28.4( \pm 2.6)$ & $-30.15( \pm 2.0)$ & $-22.65( \pm 2.0)$ \\
\hline
\end{tabular}

Reproducibility of zeta potential values, measured as differences in the mean values from the two samples, ranged from $0 \%$ to $18 \%$ (see Table 1). All DEPs were negatively charged. From 0x to $0.1 \mathrm{x}$ and from $0.1 \mathrm{x}$ to $1 \mathrm{x}$, the average zeta potential values did not change substantially. However, from 0x to 10x, DEP zeta potential values changed by $20 \%$ from $-28.4 \mathrm{mV}$ to $-22.65 \mathrm{mV}$. Sarkar and colleagues also reported a similar tendency with zeta potential changing from $-40.3 \mathrm{mV}$ to $-31 \mathrm{mV}$ as Envirox ${ }^{\mathrm{TM}}$ concentration increased from $0 \mathrm{x}$ to $10 \mathrm{x} .^{22}$ Several factors including media $\mathrm{pH}$, particle size, morphology, and composition may affect zeta potentials. ${ }^{23}$ In this study all of these factors besides media $\mathrm{pH}$ were changed to different degrees, which made the trend in zeta 
potential as a function of Envirox ${ }^{\mathrm{TM}}$ concentration not as clear and not consistent even across the two replicate samples. Our findings suggest that DEP surface charge may be affected by factors more than fuel content of nanoceria; and we did not identify a definitive role of nano ceria in affecting DEP zeta potential.

There are several studies reported that zeta potential, as a common indicator of surface charge, affects particle bioreactivity and toxicity such as cytotoxic effects ${ }^{24}$ and immune responses in primary human peripheral blood mononuclear cells. ${ }^{22}$ The current study did not provide clear evidence that DEP toxicity would be altered via altered zeta potential due to the addition of Envirox ${ }^{\mathrm{TM}}$ in the fuel.

\subsection{Effects of Envirox ${ }^{\mathrm{TM}}$ on DEP morphology and crystallinity}

The cerium content in the DEP was analysed by analytical TEM techniques; and the results are shown in Figure 1 for DEPs from the 10x fuel. Z (atomic number)-contrast HAADF-STEM imaging is useful to indicate atomic number variations within the sample, which is formed by incoherently scattered, high angle electrons, with the intensity approximately proportional to $\mathrm{Z}^{2}$. The significant contrast differences as shown by HAADFSTEM in Figure 1b, i.e. particles of high brightness mixed with structures of low brightness, imply variations in chemical composition. Indeed, as indicated by high resolution STEM-EDX analysis, the bright particles (area 1) are $\mathrm{Ce}$ - and $\mathrm{O}$ - rich in composition (Figure 1c top), while the structures of lower brightness (area 2) are mainly carbon (Figure 1c bottom). Cerium in DEPs mainly existed in the form of $\mathrm{CeO}_{2}$ as revealed by highresolution TEM (HRTEM). The lattice spacings (Figure 1d-f), are corresponding to the (111), (200), (220), and (311) inter-planar spacings of cubic cerium oxide $\left(\mathrm{CeO}_{2}\right)(0.312,0.271,0.191$, and $0.163 \mathrm{~nm})$, respectively. The details of the lattice spacings are presented in Figure S2 and Table S4 in the Supplemental Information. Images shown in Figure 1 illustrate that various size of $\mathrm{CeO}_{2}$, rather than other forms of cerium, were mixed with DEPs. Our findings are consistent with those from previous studies, suggesting that Ce reaches its highest oxidative state $\left(\mathrm{Ce}^{4+}\right)$ and exists as $\mathrm{CeO}_{2}$ very early during the DEP formation phase. ${ }^{6,7,12}$

The chemical form of cerium may be an important determinant of particle toxicity, as suggested by a recent study reporting that cerium oxide (ceria) nanoparticles are more toxic than other form of cerium particles. ${ }^{25}$ As shown in Figure 1, ceria in the DEP had a size of 100 to $200 \mathrm{~nm}$, representing particle 
agglomerates rather than the single ceria particles of 5-10 $\mathrm{nm}$ originally added into the fuel. ${ }^{12}$ The larger size agglomerates are expected to be less toxic and bio-reactive than smaller non-agglomerated particles. ${ }^{26}$
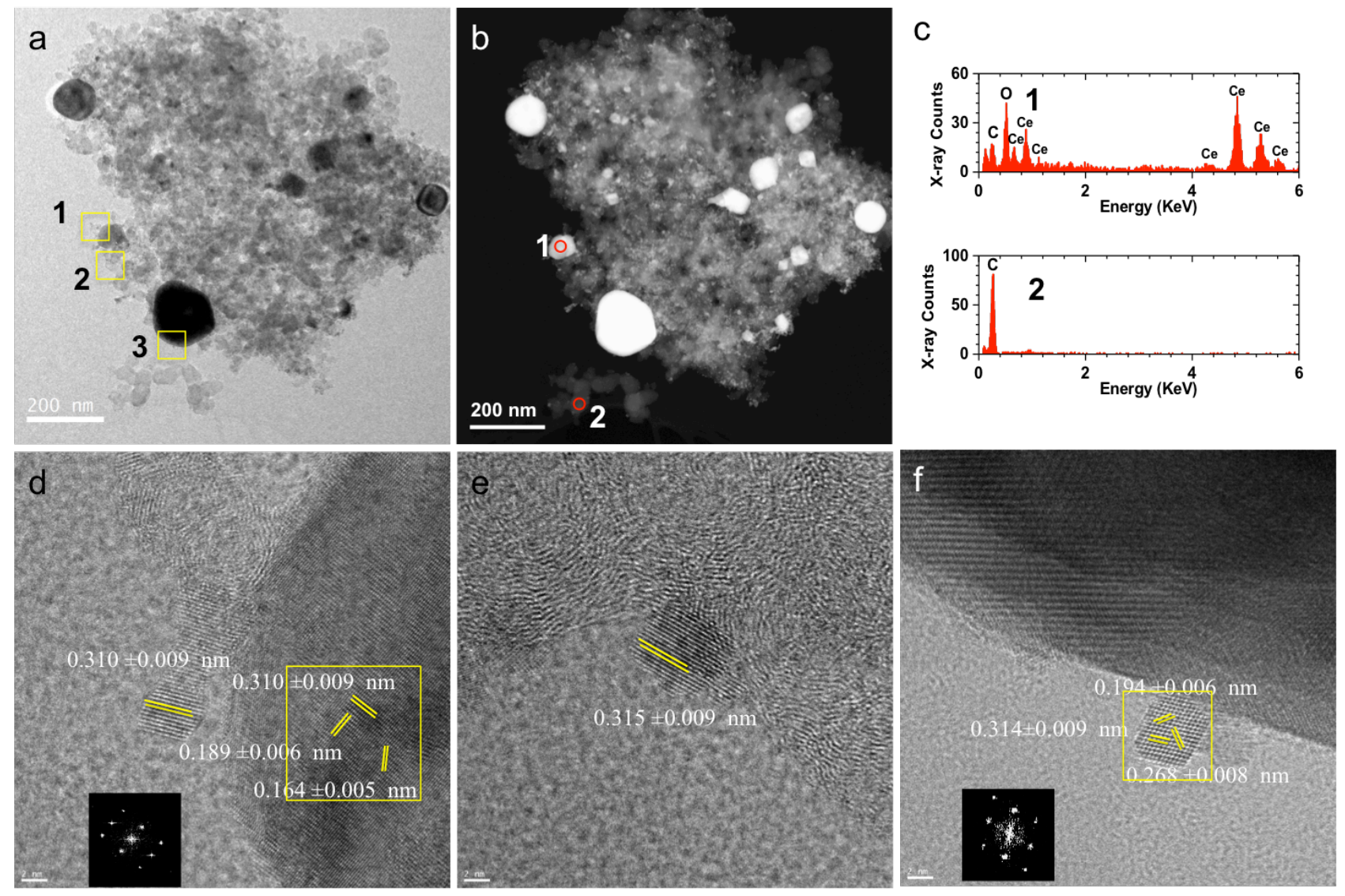

Figure 1. TEM images of DEP for diesel fuel with 10x Envirox $^{\mathrm{TM}}$ : (a) Bright field TEM (BF-TEM) images of particles; (b) the high angle annular dark field-scanning transmission electron microscopy (HAADF-STEM) image corresponding with (a); (c) STEM-dispersive X-ray spectroscopy (STEM-EDX) spectra taken from corresponding Area 1 and Area 2 as marked in (b); (d-f) high resolution TEM (HR-TEM) images taken from boxed area 1-3 in (a); Insets are the corresponding Fast Fourier Transform (FFT) patterns taken from the boxed areas, respectively. The scale of (d-f) is $2 \mathrm{~nm}$.

Furthermore, TEM images showing the morphology of DEPs for three diesel fuels (0x, 1x and 10x) are presented in Figure 2. The addition of Envirox ${ }^{\mathrm{TM}}$ seems to have no effect on the shape of the DEPs, as DEPs from all the fuels looked like spherical (or spheroidal) nano-sized or larger particles comprised of several fused DEPs. The DEP agglomeration status was hard to compare by TEM due to the limitation of small imaged areas and negative effects of drying nanoparticles on the TEM grid. (Note that the 'negative effects' here means the formation of nanoparticle aggregates. The standard TEM sample preparation typically consists of drop casting 
and drying a drop of nanoparticle suspension on a TEM grid. The drying process results in the formation of nanoparticle aggregation due to surface dewetting and the so-called 'coffee ring' effect. Therefore, it's difficult to comment on the aggregation status of nanoparticle samples prepared by this approach. This is a limitation of the method.)

Typical Raman spectra of different DEP samples are shown in Figure 3a. The D peak $\left(\sim 1350 \mathrm{~cm}^{-1}\right)$ and $\mathrm{G}$ peak $\left(\sim 1580 \mathrm{~cm}^{-1}\right)$, corresponding to disordered graphitic lattice and graphitic lattice of soot particles, respectively, ${ }^{18}$ were displayed in the first-order spectra and observed to be strongly overlapped. Further curve fitting revealed more features of the graphitic and disordered lattice of soot carbon walls, and an example for 0x is presented in Figure 3b. The peak area ratio of G peak to the sum of D1, D3 and D4 peaks provided semiquantitative characteristics of the level of graphitized carbon (crystallinity). An increasing trend for the G/D ratio implying more graphitized carbon structures, shown in Figure 4, was found for DEP with increasing concentrations of nano $\mathrm{CeO}_{2}$ in the diesel. A previous study found that compared with well-graphitized diesel soot, disordered carbon structures could facilitate oxidation of diesel soot (DEP). ${ }^{27}$ Hence, the addition of Envirox $^{\mathrm{TM}}$ is expected to decrease the oxidative potential of DEPs by increasing of particle crystallinity, one of the mechanisms underlying the effect of nano ceria on the DEP oxidative potential (see 3.4 below). On the other hand, the reduction of oxidative potential of DEPs may also decreases their toxicity. ${ }^{22}$ 


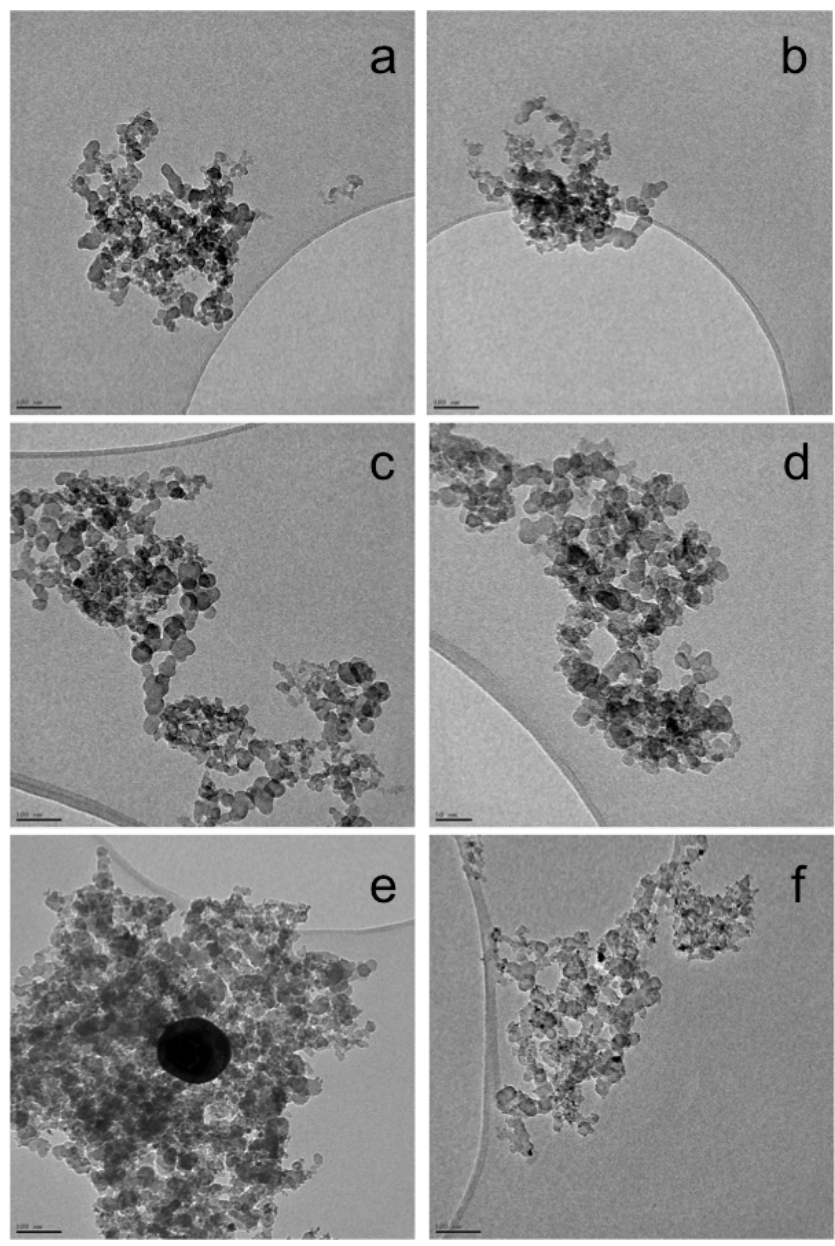

Figure 2. TEM image of DEPs for diesel fuels with varying Envirox ${ }^{\mathrm{TM}}$ concentration: $\mathrm{a}$ and $\mathrm{b}(0 \mathrm{x})$; $\mathrm{c}$ and $\mathrm{d}(1 \mathrm{x})$; e and $\mathrm{f}(10 \mathrm{x})$. The scale is $100 \mathrm{~nm}$ for $\mathrm{a}, \mathrm{b}, \mathrm{c}, \mathrm{e}$, and $\mathrm{f}$ and $50 \mathrm{~nm}$ for $\mathrm{d}$.
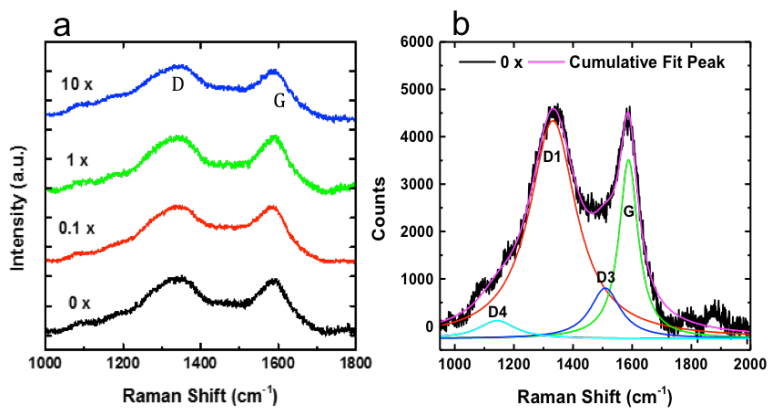

Figure 3. (a) Raman Spectra of DEPs from the four diesel fuels $(0 \mathrm{x}, 0.1 \mathrm{x}, 1 \mathrm{x}$, and 10x) with excitation laser wavelength of $633 \mathrm{~nm}$. (b) Curve fitting for a typical Raman Spectra of DEP from the 0x fuel, fitted peaks included G band $\left(\sim 1580 \mathrm{~cm}^{-1}\right.$, graphitic lattice $),{ }^{28,29} \mathrm{D} 1$ (D) band $(\sim 1350 \mathrm{~cm}-1$, disordered graphitic lattice $){ }^{28,29}$ D3 (D’) band ( 1500 cm-1, amorphous carbon $)^{30,31}$ and D4 ( 1200 cm-1, disordered graphitic lattice, ${ }^{32}$ polyenes,,$^{30,31}$ and ionic impurities ${ }^{33}$ ). 

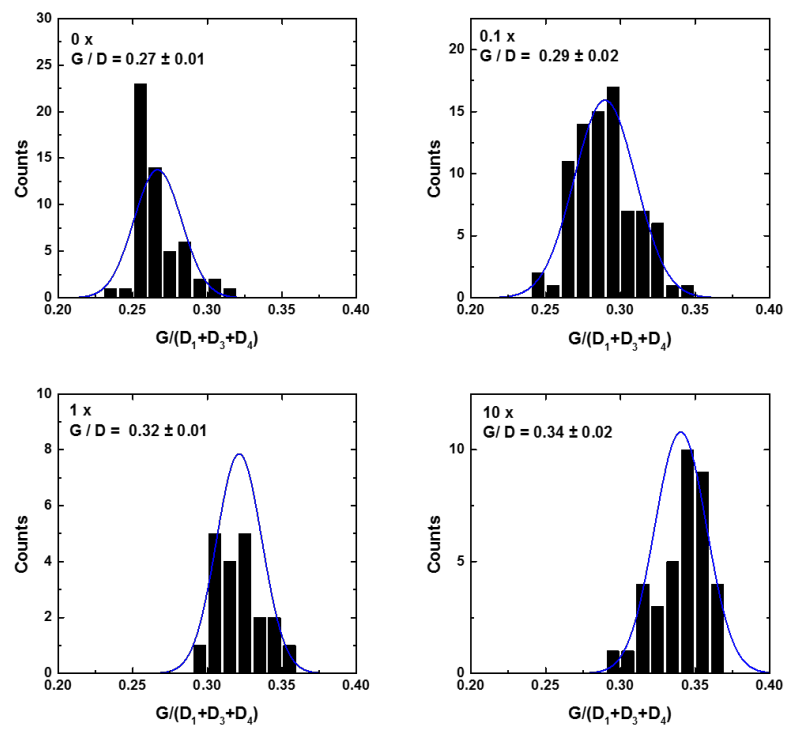

Figure 4. Distribution of G to D ratios based on Raman Spectra of the DEPs emitted from the four diesel fuels with varying concentrations of Envirox ${ }^{\mathrm{TM}}(0 \mathrm{x}, 0.1 \mathrm{x}, 1 \mathrm{x}, 10 \mathrm{x})$.

\subsection{Effects of Envirox ${ }^{\mathrm{TM}}$ on DEP chemical composition}

Results of the main elements of DEPs are shown in Table 2. It was found that the addition of Envirox ${ }^{\mathrm{TM}}$ at $0.1 \mathrm{x}$ concentration did not have much of an effect on the carbon content or nitrogen content, as compared to that in DEPs from the 0x fuel. However, further increase in the concentration of Envirox ${ }^{\mathrm{TM}}$ (at $1 \mathrm{x}$ and $10 \mathrm{x}$ ) led to the progressive reduction in carbon content with a concomitant increase in nitrogen content. The hydrogen content varied little across the four DEPs. As expected, cerium content increased with increasing Envirox ${ }^{\mathrm{TM}}$ concentrations in the fuel (Table 2). It is interesting to note that the base fuel $(0 \mathrm{x})$ generated DEPs with detectable cerium content. This is due to the use of Ce in catalysts during production (refinery) of diesel fuel. ${ }^{34}$

Table 2. Elemental analysis of the DEP for the four diesel fuels with varying Envirox ${ }^{\mathrm{TM}}$ concentration $^{\mathrm{D}}$

\begin{tabular}{|c|c|c|c|c|c|}
\hline Fuel & Carbon & Hydrogen & Cerium & Nitrogen & Other \\
\hline $0 \mathrm{x}$ & 91.84 & 2.23 & 0.30 & 0.23 & 5.40 \\
\hline $0.1 \mathrm{x}$ & 91.81 & 2.12 & 0.48 & 0.25 & 5.34 \\
\hline $1 \mathrm{x}$ & 89.63 & 2.12 & 0.73 & 0.35 & 7.17 \\
\hline $10 \mathrm{x}$ & 79.40 & 2.43 & 6.52 & 0.61 & 11.04 \\
\hline
\end{tabular}

Previously we found that increasing nanoceria concentration in the fuel resulted in increasing emissions of gaseous nitrogen species (e.g., $\mathrm{NO}$ and $\left.\mathrm{NO}_{2}\right) .{ }^{9}$ It is possible that a fraction of gaseous nitrogen species was converted into condensed-phase nitrogen-containing compounds, which explains the results reported here that 
increasing nanoceria in the fuel increased DEP nitrogen content (\%). For example, nitro-PAHs are well-known constituents of DEP. ${ }^{35}$ and nitro-PAHs and other nitro-hydrocarbons usually have lower vapor pressure than corresponding parent PAHs and the other hydrocarbons. ${ }^{36}$ Based on this hypothesis, using cerium-based fuel additives may increase the toxicity of DEP, since compared with unsubstituted PAHs, nitro-PAHs have far greater toxicity. ${ }^{37}$

The addition of Envirox ${ }^{\mathrm{TM}}$ also appears to have facilitated the oxidation of hydrocarbons to oxygenated compounds. As shown in Figure 5, DEPs from the 10x fuel had the highest OC fraction (corresponding to a decreased EC fraction) of total carbon. However, the OC versus EC change was small when Envirox ${ }^{\mathrm{TM}}$ was added at $0.1 \mathrm{x}$ and $1 \mathrm{x}$. This observation is consistent with the finding of Okuda and colleagues (2009) who reported that adding $7.5 \mathrm{ppm}$ Ce with $0.1 \mathrm{ppm}$ Pt resulted in a larger reduction in EC (54\% reduction) than OC (23\% reduction). ${ }^{38}$ The catalytic and combustion mechanism for these findings is yet to be determined..$^{39}$ Based on our observations from the present study (Section 3.3), we propose three possible mechanisms. Firstly, improved oxidation of disordered carbon by nano ceria leaves the DEP core with ordered carbon, which could adsorb more organic carbon. Secondly, more oxidized carbon was produced likely due to the incomplete oxidation of both ordered and disordered carbon. And lastly, with increasing of Envirox ${ }^{\mathrm{TM}}$ concentration, more ceria nuclei were created, which could cause the condensation of organic gases on their surface. ${ }^{12}$ The last mechanism is supported by a previous study ${ }^{12}$; however, whether and how the other two mechanisms are involved need to be addressed in future studies. Since only the proportion of OC and EC was studied in this study without knowing the specific mechanism, how these changes affect the toxicity of DEP need to be further investigated.

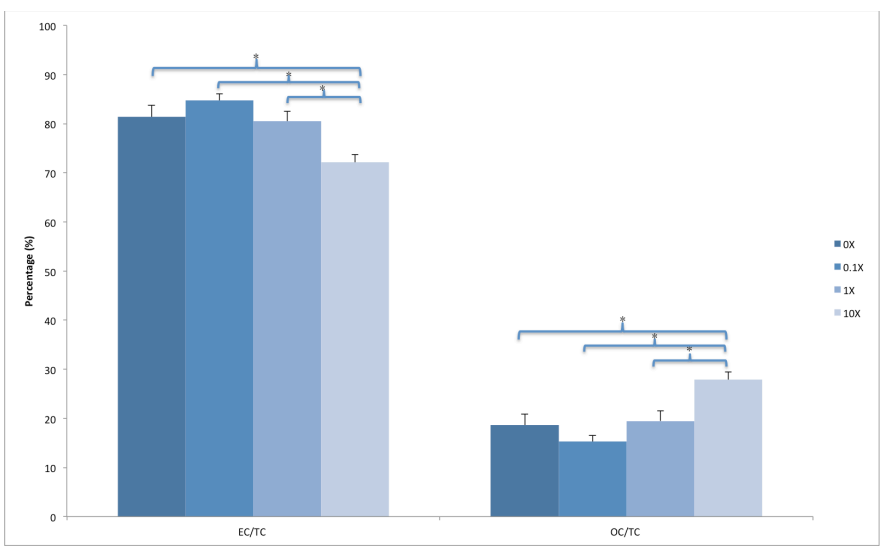


Figure 5. The ratio of elemental carbon (EC) and organic carbon (OC) to total carbon (TC) of the DEP emitted from the four diesel fuels with varying Envirox ${ }^{\mathrm{TM}}$ concentration $(0 \mathrm{x}, 0.1 \mathrm{x}, 1 \mathrm{x}$, and $10 \mathrm{x})$. Asterisk $(*)$ means a significant difference $(\mathrm{P}<0.05)$, based on two-tailed student $\mathrm{t}$ test. Error bars are constructed based on one standard deviation.

\subsection{Effects of Envirox ${ }^{\mathrm{TM}}$ on DEP oxidative potential}

One of the mechanisms by which DEPs (and particles in general) exert toxicity and bioreactivity is the ability of DEP to generate reactive oxygen species (ROS) in vitro or in vivo. ${ }^{40}$ The potency of ROS generation can be assessed using simple, chemistry-based methods. For example, as a surrogate of ROS generation potency, oxidative potentials of the DEPs and two reference materials were determined here through a redox-based assay called the ascorbate depletion test. Ascorbic acid (vitamin C) is a well-known antioxidant, and hence its depletion rate upon reacting with a substance reflects the oxidative potential of the substance..$^{41}$ As shown in Figure 6a, the rate of ascorbic acid depletion (measured as total ascorbate ions) is a function of concentration of each test material and hence represents a series of "dose-response" curves. A steeper slope in each curve corresponds to the faster depletion of ascorbic acid, and thus higher oxidative potential of the material. Among all the tested particles, pure $\mathrm{CeO}_{2}$ nanoparticles had the lowest oxidative potential, whereas DEPs from the 0x fuel (no Envirox ${ }^{\mathrm{TM}}$ added) had the highest oxidative potential. The oxidative potential values for DEPs from the $0.1 \mathrm{x}, 1 \mathrm{x}$, and $10 \mathrm{x}$ were in between those for pure $\mathrm{CeO}_{2}$ and $0 \mathrm{x}$ and they were not different from each other and from that of the NIST 2975 (a bulk and aged DEP). In general, adding nanoceria fuel additives might decrease DEP toxicity through a reduction in its ability to generate ROS, but it does not seem to have a clear dosedependent relationship.

To control for the influence of $\mathrm{CeO}_{2}$, a single compound with a low oxidative potential, in the DEP on the reduction of the oxidative potential of the entire sample, we normalized the ascorbate depletion rates by DEP $\mathrm{CeO}_{2}$ content. As shown in Figure 6b, the normalization did not change the overall trend, but the slope for the 10x DEP became steeper. This might be due to the significantly increase of organic carbon content in the $10 \mathrm{x}$ group. On the other hand, the significant increase of particle crystallinity for the 10x group was reported by Ivleva et al. to have the potential to decrease DEP oxidative potential. ${ }^{27}$ Therefore, more study should be 
conducted in order to understand the mechanisms of how these two parameters combine in influencing the overall oxidative potential of DEP as shown in Figure 6a.

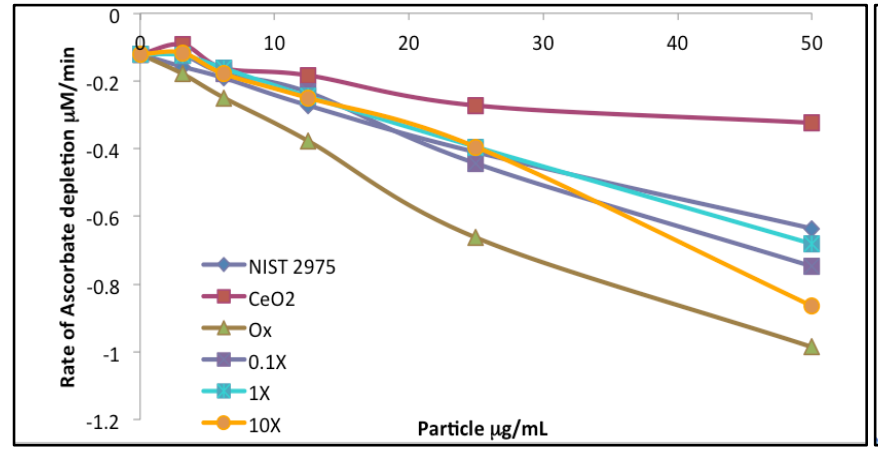

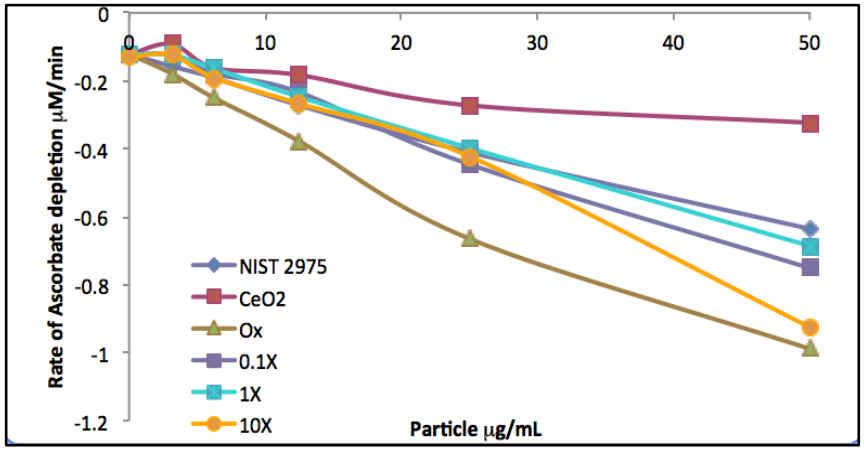

b

Figure 6. a. Rate of ascorbic acid (AA) depletion by DEP $(0 \mathrm{x}, 0.1 \mathrm{x}, 1 \mathrm{x}$ and $10 \mathrm{x})$ and two reference particles $\left(\mathrm{CeO}_{2}\right.$ and NIST 2975).b. Rate of $\mathrm{CeO}_{2}$-normalized AA depletion by DEP and control particles. NIST 2975 are bulk-generated, aged diesel exhaust particles purchased from the National Institute of Standards and Technology (NIST), Standard Reference Materials \#2975.

\subsection{The role of soot oxidation}

Ceria or nanoceria-based diesel catalysts are known to enhance soot oxidation, ${ }^{42}$ which may explain some of our findings in the present study. Firstly, the soot oxidation may have facilitated the breakdown of larger particle agglomerates into smaller ones, leading to decreases in particle size. ${ }^{9,}{ }^{19-21}$ Secondly, this oxidation process was further revealed by the Raman spectra showing the process of preferentially oxidizing the disordered carbon structure rather than the ordered (graphitized) carbon structure. Thirdly, this oxidation may contribute to the increased organic carbon to elemental carbon ratio for the $10 \mathrm{x}$ Envirox ${ }^{\mathrm{TM}}$ condition. $^{27,39}$ Finally, the soot oxidation may play a role in altering DEP surface charge and chemical composition (e.g., increasing nitrogen content). Our experimental data from this study are clearly in support of these mechanisms related to soot oxidation, a fundamental catalytic function of nanoceria added to diesel fuel.

\section{Conclusions}

Using Envirox ${ }^{\mathrm{TM}}$ as a diesel additive resulted in changes in certain physicochemical properties of emitted diesel exhaust particles (DEP), including reduced particle size, decreased total carbon content (\%), decreased disordered carbon structure, decreased elemental carbon fraction (\%) in total carbon, increased cerium and 
nitrogen content, and reduced oxidative potential. These physicochemical properties might be further altered after DEP is released into the environment, ${ }^{12}$ which needs to be addressed in future studies. Given that these physicochemical properties are important determinants of particle toxicity, it is anticipated that using nanoceria additives to diesel fuel would alter the toxicity of the emitted DEP in various ways. ${ }^{22,40,43}$ For example, the increased organized structure and decreased oxidative potential might decrease the bioreactivity of DEP, while reduced particle size may increase the diffusion rate of particles within and across the lung and decrease clearance rate in the lung, thereby increasing overall bioreactivity and toxicity. ${ }^{27,44}$ Hence, the impact on the overall DEP bioreactivity and toxicity is hard to predict solely based on physiochemical property changes observed in the present study. Our findings, nonetheless, can help future toxicological studies explain the impact of nanoceria additives on DEP toxicity and help link specific physicochemical properties and biological responses.

\section{Acknowledgements}

The study was jointly funded by the U.S. Environmental Protection Agency (STAR grant 83469302) and the U.K. Natural Environment Research Council (grant NE/H012893). The views expressed in the manuscript are solely of the authors and do not necessarily reflect those of the funding agencies.

\section{Literature Cited}

1. McClellan RO. Health-Effects of Exposure to Diesel Exhaust Particles. Annual Review of Pharmacology and Toxicology. 1987;27:279-300.

2. Sydbom A, Blomberg A, Parnia S, Stenfors N, Sandström T, Dahlen S. Health effects of diesel exhaust emissions. European Respiratory Journal. 2001;17(4):733-46.

3. Popovicheva O, Engling G, Lin KT, Persiantseva N, Timofeev M, Kireeva E, et al. Diesel/biofuel exhaust particles from modern internal combustion engines: Microstructure, composition, and hygroscopicity. Fuel. $2015 ; 157: 232-9$.

4. Popovicheva OB, Kireeva ED, Steiner S, Rothen-Rutishauser B, Persiantseva NM, Timofeev MA, et al. Microstructure and Chemical Composition of Diesel and Biodiesel Particle Exhaust. Aerosol and Air Quality Research. 2014;14(5):1392-401. 
5. Park B, Donaldson K, Duffin R, Tran L, Kelly F, Mudway I, et al. Hazard and risk assessment of a nanoparticulate cerium oxide-based diesel fuel additive - A case study. Inhal Toxicol. 2008;20(6):547-66.

6. Jung HJ, Kittelson DB, Zachariah MR. The influence of a cerium additive on ultrafine diesel particle emissions and kinetics of oxidation. Combust Flame. 2005;142(3):276-88.

7. Skillas G, Qian Z, Baltensperger U, Matter U, Burtscher H. The influence of additives on the size distribution and composition of particles produced by diesel engines. Combustion Science and Technology. 2000;154:259-73.

8. Summers JC, Van Houtte S, Psaras D. Simultaneous control of particulate and NO x emissions from diesel engines. Applied Catalysis B: Environmental. 1996;10(1):139-56.

9. Zhang JF, Nazarenko Y, Zhang L, Calderon L, Lee KB, Garfunkel E, et al. Impacts of a Nanosized Ceria Additive on Diesel Engine Emissions of Particulate and Gaseous Pollutants. Environ Sci Technol. 2013;47(22):13077-85.

10. Bell ML. Assessment of the health impacts of particulate matter characteristics. Research Report (Health Effects Institute). 2012(161):5-38.

11. Franck U, Odeh S, Wiedensohler A, Wehner B, Herbarth O. The effect of particle size on cardiovascular disorders-The smaller the worse. Science of the Total Environment. 2011;409(20):4217-21.

12. Gantt B, Hoque S, Fahey KM, Willis RD, Delgado-Saborit JM, Harrison RM, et al. Factors Affecting the Ambient Physicochemical Properties of Cerium-Containing Particles Generated by Nanoparticle Diesel Fuel Additive Use. Aerosol Science and Technology. 2015;49(6):371-80.

13. Sajeevan AC, Sajith V. Diesel Engine Emission Reduction Using Catalytic Nanoparticles: An Experimental Investigation. Journal of Engineering. 2013;2013.

14. Cassee FR, van Balen EC, Singh C, Green D, Muijser H, Weinstein J, et al. Exposure, Health and Ecological Effects Review of Engineered Nanoscale Cerium and Cerium Oxide Associated with its Use as a Fuel Additive. Critical Reviews in Toxicology. 2011;41(3):213-29.

15. Sarkar S, Zhang L, Subramaniam P, Lee K-B, Garfunkel E, Strickland PAO, et al. Variability in bioreactivity linked to changes in size and zeta potential of diesel exhaust particles in human immune cells. PLoS One. 2014;9(5):e97304.

16. Birch ME, Cary RA. Elemental carbon-based method for monitoring occupational exposures to particulate diesel exhaust. Aerosol Science and Technology. 1996;25(3):221-41. 
17. Turpin B, Weisel C, Morandi M, Colome S, Stock T, Eisenreich S, et al. Relationships of Indoor, Outdoor, and Personal Air (RIOPA): part II. Analyses of concentrations of particulate matter species. Research Report (Health Effects Institute). 2007(130 Pt 2):1-77; discussion 9-92.

18. Sadezky A, Muckenhuber H, Grothe H, Niessner R, Poschl U. Raman micro spectroscopy of soot and related carbonaceous materials: Spectral analysis and structural information. Carbon. 2005;43(8):1731-42.

19. Mathis U, Mohr M, Kaegi R, Bertola A, Boulouchos K. Influence of diesel engine combustion parametes on primary soot particle diameter. Environ Sci Technol. 2005;39(6):1887-92.

20. Tree DR, Svensson KI. Soot processes in compression ignition engines. Progress in Energy and Combustion Science. 2007;33(3):272-309.

21. Harris SJ, Maricq MM. Signature size distributions for diesel and gasoline engine exhaust particulate matter. Journal of Aerosol Science. 2001;32(6):749-64.

22. Sarkar S, Zhang L, Subramaniam P, Lee KB, Garfunkel E, Strickland PAO, et al. Variability in Bioreactivity Linked to Changes in Size and Zeta Potential of Diesel Exhaust Particles in Human Immune Cells. PLoS One. 2014;9(5):12.

23. Yukselen-Aksoy Y, Kaya A. A study of factors affecting on the zeta potential of kaolinite and quartz powder. Environmental Earth Sciences. 2011;62(4):697-705.

24. Bakand S, Hayes A. Toxicological considerations, toxicity assessment, and risk management of inhaled nanoparticles. International Journal of Molecular Sciences. 2016;17(6):929.

25. Arnold M, Badireddy A, Wiesner M, Di Giulio RT, Meyer J. Cerium oxide nanoparticles are more toxic than equimolar bulk cerium oxide in Caenorhabditis elegans. Archives of environmental contamination and toxicology. 2013;65(2):224-33.

26. Murphy S, Berube K, Richards R. Bioreactivity of carbon black and diesel exhaust particles to primary Clara and type II epithelial cell cultures. Occupational and environmental medicine. 1999;56(12):813-9.

27. Ivleva NP, Messerer A, Yang X, Niessner R, Poschl U. Raman microspectroscopic analysis of changes in the chemical structure and reactivity of soot in a diesel exhaust aftertreatment model system. Environ Sci Technol. 2007;41(10):3702-7.

28. Tuinstra F, Koenig JL. Raman spectrum of graphite. Journal of Chemical Physics. 1970;53(3):1126-\&. 
29. Wang Y, Alsmeyer DC, McCreery RL. Raman-spectroscopy of carbon materials structural basis of observed spectra. Chemistry of Materials. 1990;2(5):557-63.

30. Dippel B, Jander H, Heintzenberg J. NIR FT Raman spectroscopic study of flame soot. Physical Chemistry Chemical Physics. 1999;1(20):4707-12.

31. Dippel B, Heintzenberg J. Soot characterization in atmospheric particles from different sources by NIR FT Raman spectroscopy. Journal of Aerosol Science. 1999;30:S907-S8.

32. Aljishi R, Dresselhaus G. Lattice dynamical model for graphite. Physical Review B. 1982;26(8):4514-22.

33. Cuesta A, Dhamelincourt P, Laureyns J, Martinezalonso A, Tascon JMD. Raman microprobe studies on carbon materials. Carbon. 1994;32(8):1523-32.

34. Schelter EJ. Cerium under the lens. Nature chemistry. 2013;5(4):348-.

35. Huang L, Bohac SV, Chernyak SM, Batterman SA. Composition and Integrity of PAHs, Nitro-PAHs, Hopanes, and Steranes in Diesel Exhaust Particulate Matter. Water Air and Soil Pollution. 2013;224(8):14.

36. Crimmins BS, Baker JE. Improved GC/MS methods for measuring hourly PAH and nitro-PAH concentrations in urban particulate matter. Atmospheric Environment. 2006;40(35):6764-79.

37. Atkinson R, Arey J. Atmospheric chemistry of gas-phase polycyclic aromatic hydrocarbons: formation of atmospheric mutagens. Environmental health perspectives. 1994;102(Suppl 4):117.

38. Okuda T, Schauer JJ, Olson MR, Shafer MM, Rutter AP, Walz KA, et al. Effects of a Platinum-Cerium Bimetallic Fuel Additive on the Chemical Composition of Diesel Engine Exhaust Particles. Energy \& Fuels. 2009;23:4974-80. 39. Jelles SJ, Makkee M, Moulijn JA. Ultra low dosage of platinum and cerium fuel additives in diesel particulate control. Topics in Catalysis. 2001;16(1-4):269-73.

40. Pan C-JG, Schmitz DA, Cho AK, Froines J, Fukuto JM. Inherent redox properties of diesel exhaust particles: catalysis of the generation of reactive oxygen species by biological reductants. Toxicol Sci. 2004;81(1):225-32.

41. Whitekus MJ, Li N, Zhang M, Wang M, Horwitz MA, Nelson SK, et al. Thiol antioxidants inhibit the adjuvant effects of aerosolized diesel exhaust particles in a murine model for ovalbumin sensitization. The Journal of Immunology. 2002;168(5):2560-7.

42. Fino D, Bensaid S, Piumetti M, Russo N. A review on the catalytic combustion of soot in Diesel particulate filters for automotive applications: From powder catalysts to structured reactors. Applied Catalysis A: General. 2016;509:75-96. 
43. Morimoto Y, Izumi H, Yoshiura Y, Tomonaga T, Oyabu T, Myojo T, et al. Pulmonary toxicity of welldispersed cerium oxide nanoparticles following intratracheal instillation and inhalation. J Nanopart Res. 2015;17(11):1-16.

44. Oxidative Stress and Air Pollution Exposure. Journal of Toxicology. 2011;2011. 